OPEN ACCESS

Edited by:

Musharraf Jelani,

Islamia College University, Pakistan

Reviewed by:

Bixia Zheng,

Nanjing Children's Hospital, China Yonatan Perez,

University of California, San Francisco,

United States

Fu Xiong,

Southern Medical University, China

*Correspondence:

Xue Zhang

xuezhang@pumc.edu.cn

Rongrong Wang

rongrongbw/@ibms.pumc.edu.cn

${ }^{\dagger}$ These authors have contributed equally to this work

Specialty section

This article was submitted to Genetics of Common and Rare

Diseases,

a section of the journa

Frontiers in Pediatrics

Received: 19 July 2020 Accepted: 04 November 2020 Published: 01 December 2020

Citation:

Sun L, Khan A, Zhang H, Han S,

Habulieti $X$, Wang $R$ and Zhang $X$ (2020) Phenotypic Characterization of

Intellectual Disability Caused by

MBOAT7 Mutation in Two

Consanguineous Pakistani Families.

Front. Pediatr. 8:585053.

doi: 10.3389/fped.2020.585053

\section{Phenotypic Characterization of Intellectual Disability Caused by MBOAT7 Mutation in Two Consanguineous Pakistani Families}

\author{
Liwei Sun ${ }^{\dagger}$, Amjad Khan ${ }^{\dagger}$, Han Zhang, Shirui Han, Xiaerbati Habulieti, Rongrong Wang* \\ and Xue Zhang*
}

State Key Laboratory of Medical Molecular Biology, McKusick-Zhang Center for Genetic Medicine, School of Basic Medicine Peking Union Medical College, Institute of Basic Medical Sciences Chinese Academy of Medical Sciences, Beijing, China

A homozygous in-frame deletion (c. 758_778del; p. Glu253_Ala259del) in membrane-bound O-acyltransferase family member 7 (MBOAT7), also known as lysophosphatidylinositol acyltransferase (LPIAT1), was previously reported to be the genetic cause of intellectual disability (ID) in consanguineous families from Pakistan. Here, we identified two additional Pakistani consanguineous families with severe ID individuals sharing the same homozygous variant. Thus, we provide further evidence to support this MBOAT7 mutation as a potential founder variant. To understand the genotype-phenotype relationships of the in-frame deletion in the MBOAT7 gene, we located the variant in the fifth transmembrane domain of the protein and determined that it causes steric hindrance to the formation of an $\alpha$-helix and hydrogen bond, possibly influencing its effectiveness as a functional transmembrane protein. Moreover, extensive neuropsychological observations, clinical interviews and genetic analysis were performed on 6 patients from the 2 families. We characterized the phenotype of the patients and noted the serious outcome of severe paraplegia. Thus, optimal management for symptom alleviation and appropriate screening in these patients are crucial.

Keywords: in-frame deletion, Pakistani consanguineous families, intellectual disability, founder effect, MBOAT7 gene

\section{INTRODUCTION}

Intellectual disability (ID) is a neurodevelopmental disorder characterized by substantial limitations in intellectual functioning and adaptive behavior (1). ID has an estimated prevalence of $1-3 \%$ worldwide and an increased prevalence among inbred consanguineous populations (2). ID shows extreme clinical and genetic heterogeneity. It can occur in isolation or in combination with congenital malformations or other neurological features, such as epilepsy, sensory impairment and autism spectrum disorders (ASD), and its severity is highly variable, ranging from mild to severe. The genetics of ID are heterogenetic with variable causes, including chromosomal aberrations $(3,4)$, copy number variations (CNVs) $(5,6)$, autosomal dominant $(7)$, autosomal recessive $(8,9)$, and $\mathrm{X}$-linked variants (10). De novo mutation is a major cause of sporadic ID cases among outbred populations, while autosomal recessive intellectual disability (ARID) is the leading inheritance 
form of ID in countries with frequent parental consanguinity $(11,12)$. Since membrane-bound O-acyltransferase family member 7 (MBOAT7, OMIM 606048) was reported as the causative gene for ID in six consanguineous ID families from Pakistan for the first time (13), to date, 16 mutations in the MBOAT7 from a total of 21 families have been observed, including 7 frameshift mutations (13-17), 2 splice mutations
$(13,18), 3$ non-sense mutations (16, 17), 2 missense mutations $(12,16)$, a 21 -bp deletion (13), an 11,594bp deletion (16), and an indel variant (19). Heterogeneous clinical features were associated with MBOAT7 defect, such as moderate to severe intellectual disability, epilepsy, developmental delay, attention-deficit hyperactivity disorder (ADHD), microcephaly or macrocephaly, and autistic features. Here, we delineated the

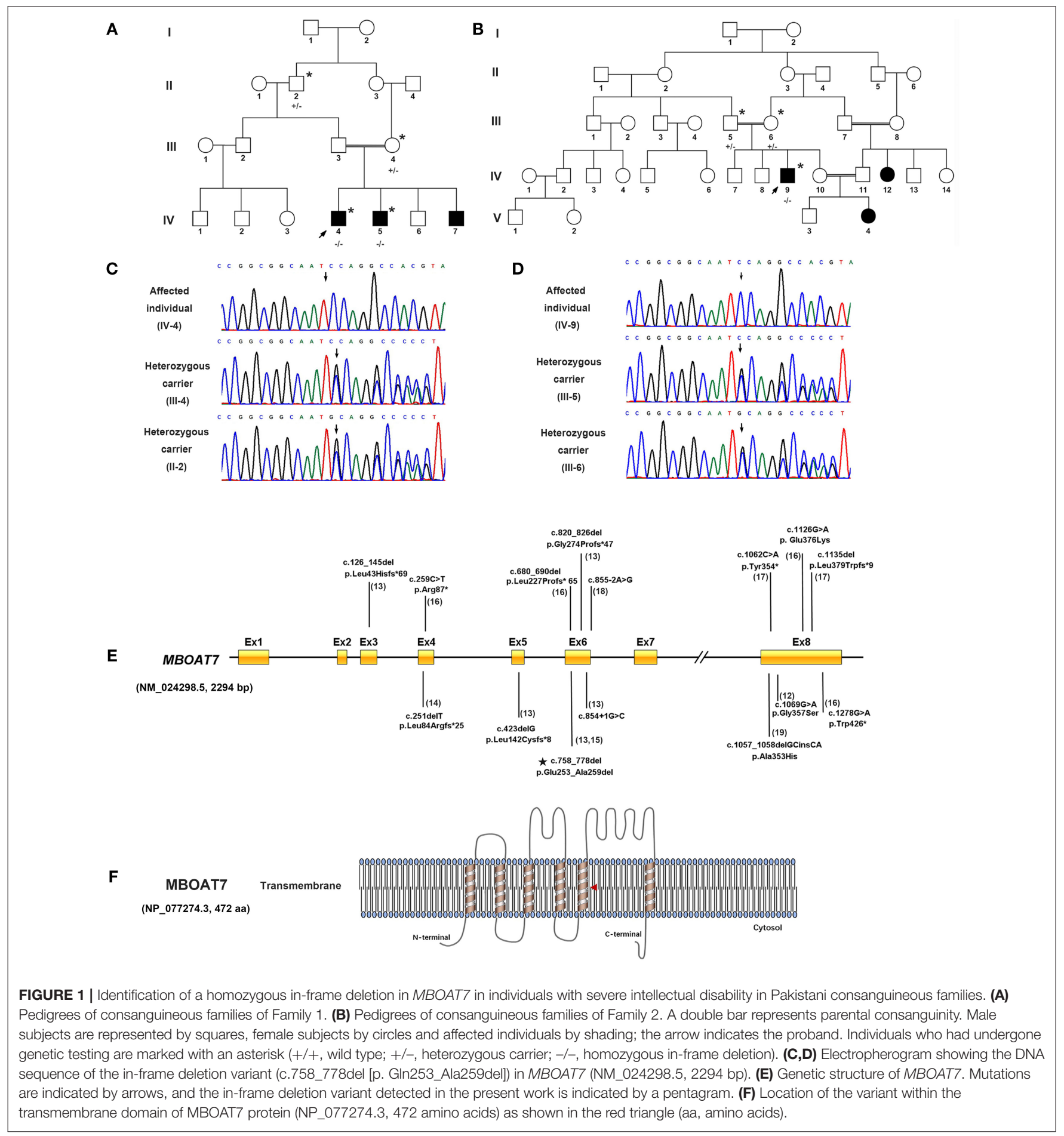


detailed clinical and genetic data of individuals with severe ID from two consanguineous Pakistan families harboring the same in-frame deletion in MBOAT7. We also performed extensive neuropsychological observations and clinical interviews on all 6 affected individuals from families. We found more complex psychiatric dysfunction or behavioral problems, such as feeding refusal, self-injurious behavior and severe paraplegia, in the probands in addition to features reported previously, broadening the clinical manifestation spectrum.

\section{MATERIALS AND METHODS}

\section{Ethics and Consent Statement}

Clinical information and blood samples were collected from the probands and available family members, and informed consent was obtained. Genetic testing was performed in accordance with the Helsinki Declaration and was approved by the Peking Union Medical College Institutional Review Board.

\section{Patients and DNA Extraction}

We recruited six patients with severe ID from two consanguineous families from the Khyber Pakhtunkhwa Province of Pakistan. Peripheral blood samples $(3-5 \mathrm{ml})$ were collected for genomic DNA extraction using the QIAamp DNA Blood Midi Kit (Qiagen, Hilden, Germany) and quantified using a Nanodrop 2000 spectrophotometer (Thermo Scientific, Waltham, MA, United States).

\section{Whole-Exome Sequencing}

Whole-exome sequencing (WES) was performed to detect variants in the proband and available family members (Family 1: II-2, III-4, IV-4, IV-5; Family 2: III-5, III-6, IV-9, IV12). Sequencing libraries were generated using the Agilent SureSelect Human All Exon V6 kit (Agilent Technologies, CA, USA). DNA libraries were sequenced using an Illumina HiSeq platform with a $100 \times$ read depth. Valid sequencing data were mapped to the reference human genome (UCSC hg19) using Burrows-Wheeler Aligner (BWA) software. Samtools (20) mpileup and bcftools were used to perform variant calling and identify SNPs, insertions and deletions (InDels). ANNOVAR (21) was performed to annotate in VCF (Variant Call Format). Functional annotation was performed based on the databases such as dbSNP, 1000 Genome, Consensus CDS, RefSeq, Ensembl and UCSC.

\section{Mutation Analysis}

Variants were filtered based on the following criteria: [1] occurring in coding regions and/or splice sites; [2] nonsynonymous; [3] found at $<0.1 \%$ frequency (Single Nucleotide Polymorphism database [dbSNP] and Exome Variant Server); and [4] homozygous in consanguineous families. The variants were further confirmed by PCR amplification using specific primers (forward primer: 5'-CTGCTGGGTCTTGGGAAG-3'; reverse primer: 5'-TGCTGTTCCTGCTCTCCTCT-3'). Sanger sequencing was performed for further validation using standard protocols. The PCR products were sequenced using ABI
BigDye3.1 (Applied Biosystems, Foster City, CA, USA) and were analyzed using the ABI 3730XL sequencer.

\section{Bioinformatic Pathogenicity Predictions}

The pathogenicity for the in-frame deletion was predicted by the in silico prediction tools PROVEAN (http://provean.jcvi. org/index.php), Mutation Taster (http://www.Mutationtaster. org/), and MutPred-Indel (http://mutpred2.mutdb.org/cgi-bin/ mutpred2_output.py).

\section{Molecular Modeling and Structural Analysis}

The 3D modeled structures of the MBOAT7 proteins for the wildtype and mutant types were prepared using homology modeling in SWISS-MODEL (https://swissmodel.expasy.org/). Structural analysis and attribution of the residue interaction networks to the protein function were analyzed and visualized by PyMOL software (https://pymol.org/2/).

\section{RESULTS}

\section{Clinical Characterization}

\section{Family 1}

In family 1 (Figure 1A), the proband (IV-4) is an 11-yearold boy who had severe intellectual disability. When he was 2-4 years old, he presented with early-onset febrile epilepsy, severe speech and language communication disorders, and developmental delay. He also had symptoms of feeding refusal. Remarkably, he presented with self-injurious behavior, banging of the head against the wall or hand, screaming at home, particularly during epileptic attacks, and aggressive behavior. Enuresis and somniloquy were observed. He had dysmorphic features, including large and low set ears, a depressed nasal bridge, strabismus, epicanthus, a flat philtrum and relatively thin upper lips with mild wide spacing of teeth. At the last examination (11 years of age), his weight was $45.9 \mathrm{~kg}$ (+1.1 SD), his height was $121.6 \mathrm{~cm}(-3.4 \mathrm{SD})$, and the $\mathrm{OFC}$ was $52.1 \mathrm{~cm}$ ( $-0.9 \mathrm{SD})$. Karyotype analysis was normal (46 XY). Other clinical features, such as hearing, cardiac, respiratory, nose, nails and skin, appeared normal. The proband also had two brothers (IV-5 and IV-7) who presented with the same symptoms, and all these individuals presented the disease features when they were 2-4 years old.

\section{Family 2}

In Family 2 (Figure 1B), the proband (IV: 9) is a 20year-old young man. He walked at 18 months of age and showed gross and fine motor incoordination. He presented with severe speech delay and non-verbal learning disorders, social impairment, cognitive disorders, and developmental delays. He was found to have severe early-onset epilepsy. At the last examination (20 years of age), he measured $169.7 \mathrm{~cm}$ in height, weighed $65.7 \mathrm{~kg}$ and had an OFC (occipital circumference) of $54 \mathrm{~cm}(-0.3 \mathrm{SD})$. Importantly, he had severe self-injurious behavior and ADHD. Dysmorphic features include prominent eyes with mild hypertelorism and downslanting palpebral fissures. In addition to the initial motor incoordination 
TABLE 1 | Summary of the clinical features of the present study and published cases associated with MBOAT7 variants.

\begin{tabular}{|c|c|c|c|c|c|c|c|c|c|c|c|c|c|c|}
\hline \multicolumn{7}{|c|}{ Present Study } & \multirow{2}{*}{$\begin{array}{l}\text { Khan } \\
\text { et al. (15) }\end{array}$} & \multirow{2}{*}{$\begin{array}{l}\text { Johansen } \\
\text { et al. (13) }\end{array}$} & \multirow{2}{*}{$\begin{array}{l}\text { Hu et al. } \\
(12) \\
1\end{array}$} & \multirow{2}{*}{$\begin{array}{l}\begin{array}{l}\text { Santos- } \\
\text { Cortez } \\
\text { et al. (14) }\end{array} \\
1\end{array}$} & \multirow{2}{*}{$\begin{array}{l}\text { Yalnizoglu } \\
\text { et al. (16) }\end{array}$} & \multirow{2}{*}{$\begin{array}{l}\begin{array}{l}\text { Jacher } \\
\text { et al. (18) }\end{array} \\
1\end{array}$} & \multirow{2}{*}{$\begin{array}{l}\text { Heidari } \\
\text { et al. (17) }\end{array}$} & \multirow{2}{*}{$\begin{array}{l}\text { Farnè } \\
\text { et al. (19) }\end{array}$} \\
\hline Number of Families & & Family 1 & & & Family 2 & & & & & & & & & \\
\hline $\begin{array}{l}\text { Gender (number of } \\
\text { individuals) }\end{array}$ & Male (IV-4) & Male (IV-5) & Male (IV-7) & Male (IV-9) & Female (IV-12) & Female (V-4) & $\begin{array}{l}\text { Male (4); } \\
\text { Female (3) }\end{array}$ & $\begin{array}{l}\text { Male (7); } \\
\text { Female (9) }\end{array}$ & $\begin{array}{l}\text { Male (3); } \\
\text { Female (0) }\end{array}$ & $\begin{array}{l}\text { Male (2); } \\
\text { Female (2) }\end{array}$ & $\begin{array}{l}\text { Male (5); } \\
\text { Female (7) }\end{array}$ & $\begin{array}{l}\text { Male (0); } \\
\text { Female (1) }\end{array}$ & $\begin{array}{l}\text { Male (2); } \\
\text { Female (1) }\end{array}$ & $\begin{array}{l}\text { Male (0); } \\
\text { Female (1) }\end{array}$ \\
\hline Origin & Pakistan & Pakistan & Pakistan & Pakistan & Pakistan & Pakistan & Pakistan & $\begin{array}{l}\text { Egypt (3/16); } \\
\text { Pakistan } \\
\text { (9/16); } \\
\text { Jordan (2/16); } \\
\text { Iraq (2/16) }\end{array}$ & $\operatorname{Iran}(3 / 3)$ & Pakistan & $\begin{array}{l}\text { Turkey } \\
(12 / 12)\end{array}$ & NA & $\operatorname{Iran}(3 / 3)$ & Italy (1/1) \\
\hline $\begin{array}{l}\text { Development } \\
\text { Intellectual } \\
\text { disability }\end{array}$ & + & + & + & + & + & + & + & $16 / 16$ & $3 / 3$ & $4 / 4$ & $12 / 12$ & $1 / 1$ & $3 / 3$ & $1 / 1$ \\
\hline $\begin{array}{l}\text { Developmental } \\
\text { delay }\end{array}$ & + & + & + & + & + & + & + & $16 / 16$ & $0 / 3$ & NA & $12 / 12$ & $1 / 1$ & $3 / 3$ & $1 / 1$ \\
\hline $\begin{array}{c}\text { Speech } \\
\text { delay/impairment }\end{array}$ & + & + & + & + & + & + & + & $14 / 16$ & $0 / 3$ & $4 / 4$ & $12 / 12$ & $1 /$ & $\begin{array}{l}\text { A few } \\
\text { words (3/3) }\end{array}$ & $1 / 1$ \\
\hline Severe paraplegia ${ }^{*}$ & NA & NA & NA & + & NA & NA & NA & NA & NA & NA & NA & NA & NA & NA \\
\hline $\begin{array}{l}\text { Neurological } \\
\text { features } \\
\text { Seizures }\end{array}$ & + & + & + & + & + & + & + & $16 / 16$ & $3 / 3$ & $4 / 4$ & $11 / 12$ & $1 / 1$ & $3 / 3$ & $1 / 1$ \\
\hline$A D H D$ & NA & NA & NA & + & + & + & NA & $0 / 16$ & NA & NA & NA & $1 / 1$ & NA & NA \\
\hline $\begin{array}{l}\text { Behavior } \\
\text { Impairment of } \\
\text { social interaction }\end{array}$ & + & + & + & + & + & + & + & $16 / 16$ & NA & NA & $12 / 12$ & $1 / 1$ & $3 / 3$ & $1 / 1$ \\
\hline $\begin{array}{l}\text { Self-injurious } \\
\text { behavior }{ }^{*}\end{array}$ & + & + & + & + & NA & NA & NA & NA & NA & NA & NA & NA & NA & NA \\
\hline Feeding refusal ${ }^{*}$ & + & + & + & NA & NA & NA & NA & NA & NA & NA & NA & NA & NA & NA \\
\hline Hyperphagia/obesity & NA & NA & NA & NA & NA & NA & NA & NA & NA & NA & NA & $1 / 1$ & NA & $1 / 1$ \\
\hline Autistic features & NA & NA & NA & NA & NA & NA & $3 / 7$ & $7 / 16$ & $3 / 3$ & $4 / 4$ & $4 / 12$ & $1 / 1$ & $2 / 3$ & $1 / 1$ \\
\hline $\begin{array}{l}\text { Dysmorphic } \\
\text { features }\end{array}$ & $\begin{array}{l}\text { Low set ears, } \\
\text { depressed } \\
\text { nasal bridge, } \\
\text { strabismus, } \\
\text { normal lips }\end{array}$ & NA & NA & $\begin{array}{l}\text { Prominent } \\
\text { eyes with mild } \\
\text { hypertelorism; } \\
\text { down slanting } \\
\text { palpebral } \\
\text { fissures }\end{array}$ & NA & NA & NA & NA & Strabismus & NA & $\begin{array}{l}\text { Apathetic } \\
\text { face, large } \\
\text { ears, deep } \\
\text { set eyes, } \\
\text { short } \\
\text { philtrum, } \\
\text { and broad } \\
\text { forehead }\end{array}$ & $\begin{array}{l}\text { Nystagmus, } \\
\text { strabismus } \\
\text { with } \\
\text { amblyopia }\end{array}$ & NA & $\begin{array}{l}\text { Curly hair, } \\
\text { heavy } \\
\text { eyebrows, } \\
\text { synophrys, } \\
\text { high nasal } \\
\text { bridge, full } \\
\text { cheeks, and } \\
\text { facial } \\
\text { hirsutism }\end{array}$ \\
\hline
\end{tabular}

$N A$, not applicable; $A D H D$, attention-deficit hyperactivity disorder.

Note: +, feature presented.

" indicates the expanding features observed in our study. 
A

p. Glu253_Ala259del

Homo sapiens

Bos taurus

Mus musculus

Rattus norvegicus

Pan troglodytes

Xenopus tropicalis

Oryctolagus cuniculus

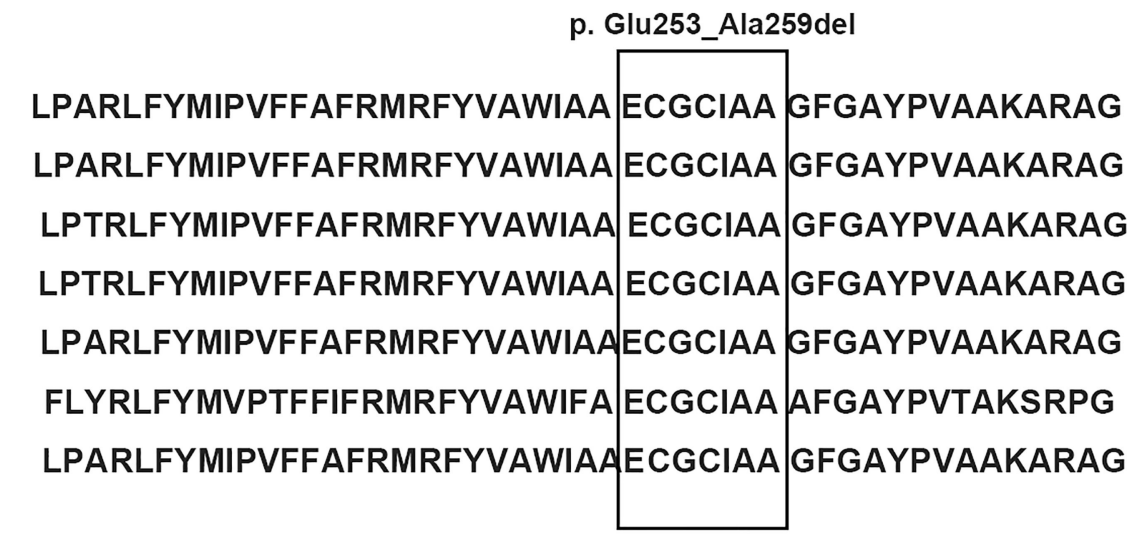

B

Nomal
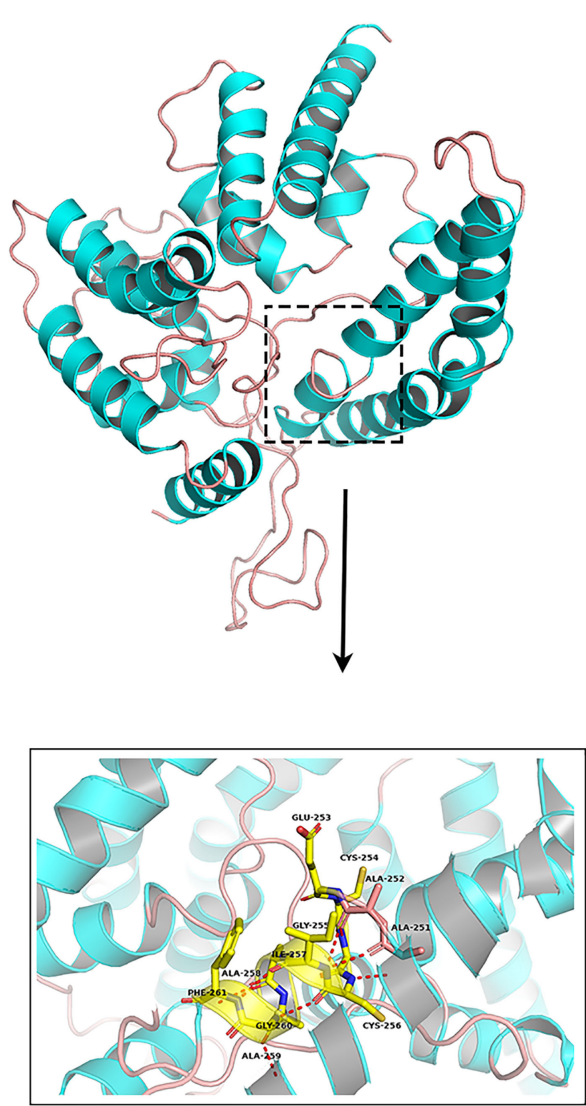

Deletion
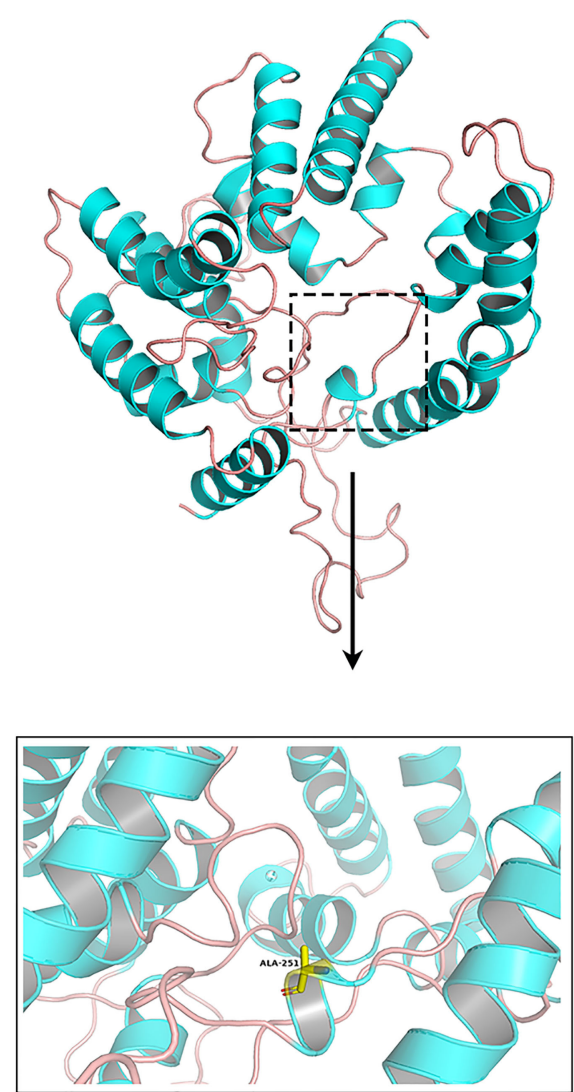

FIGURE 2 | Conservation analysis and molecular modeling of wild-type and mutant MBOAT7 protein. (A) Conservation analysis of the in-frame deletion variant (c.758_778del [p. Gln253_Ala259del]) in the MBOAT7 protein. MBOAT7 protein sequence alignment from different organisms indicates that the in-frame deletion variant is highly conserved in mammalian and vertebrate species: Homo sapiens (NP_077274.3), Bos taurus (NP_001068620.1), Mus musculus (NP_084210.2), Rattus norvegicus (NP_001128450.1), Pan troglodytes (XP_009434639.1), Xenopus tropicalis (XP_012822891.2), Oryctolagus cuniculus (DP001062.1). (B) Three-dimensional schematic of the structure of normal MBOAT7 protein (on the left) and the MBOAT7 protein with an in-frame deletion ( $p$. Gln253_Ala259del) (on the right). The alteration in the three-dimensional positioning of the in-frame deletion causes steric hindrance to the formation of helices and hydrogen bonds in the MBOAT7 protein. The structure highlighted by the dotted box can be viewed magnified as indicated by the arrow. The red dots show hydrogen bonds.

during infancy, our clinical follow-up also demonstrated that the symptom had developed into severe paraplegia, with his walking ability lost completely and becoming bedridden.
Two affected females (IV: 12 and V: 4) in the family also presented with speech delays, ID, DD, seizures, ADHD, and mild social impairment. The clinical manifestations of all six 
severe ID individuals from the two families are summarized in Table 1.

\section{Genomic Sequencing and Analysis}

Whole-exome sequencing identified the same in-frame deletion in exon 6 (c.758_778del, p. Glu253_Ala259del) of MBOAT7 (GenBank: NM_024298.5) in the three available affected individuals. The variant was confirmed by Sanger sequencing (Figures 1C,D), and it segregated with the disease as a fully penetrant recessive trait within families. MBOAT7 harbored eight exons and four protein-coding transcripts, and the variants described until now affected all protein-coding transcripts, as shown (13, 16, 18) (Figure 1E). The MBOAT7 variant (c. 758_778del; p. Glu253_Ala259del) has an allele frequency of 0.000032 within the global population and an allele frequency of 0.0001 within the Asian population in gnomAD (The Genome Aggregation Database, gnomAD) and an allele frequency of 0.000098 within the global population and an allele frequency of 0.00018 within the Asian population in ExAC (The Exome Aggregation Consortium, ExAC). It is located within highly conserved amino acid residues (Figure 2A). The variant is interpreted as pathogenic in Clinvar and dbSNP and is considered deleterious and disease causing by pathogenicity analysis using several in silico prediction tools, including PROVEAN, Mutation Taster, and MutPred-Indel.

\section{In silico Analysis and Protein Structure Modeling}

Because MBOAT7 is involved in the Lands' cycle, which is a metabolic pathway in the endoplasmic reticulum compartment, it influences the composition of membranes by remodeling the acyl chain composition of phospholipids by anchoring to endomembranes by six transmembrane domains (22). The variant detected in our study was located in the fifth transmembrane domain (Figure 1F). The wild-type and mutant MBOAT7 protein structures showed that the alteration in the three-dimensional positioning of the in-frame deletion caused steric hindrance to the formation of an $\alpha$-helix and hydrogen bond, which may influence its transmembrane protein function (Figure 2B).

\section{DISCUSSION}

In this study, we identified a homozygous in-frame deletion (c.758_778del; p. Glu253_Ala259del) in MBOAT7 causing severe intellectual disability in two consanguineous Pakistani families. The variant has been reported in Pakistani families previously, indicating it could be a regional prevalent founder mutation. We characterized the phenotypes in 6 subjects from the two families, all of whom presented with clinical signs during infancy or early childhood, including at 18 months old (3/6 subjects) and 24 years old ( $3 / 6$ subjects). Severe ID accompanied by features of speech impairment, social interaction skills impairment, development delays and locomotor incoordination was observed in all of the subjects. Moreover, they all manifested early childhood-onset epilepsy, supporting epilepsy as a consistent feature of $M B O A T 7$-related ID. Additionally, we characterized unique features, such as severe paraplegia (1/6 subjects), feeding refusal (3/6 subjects), and self-injurious behavior ( $4 / 6$ subjects). In contrast to the feature of feeding refusal, hyperphagia and obesity were previously reported in 4 patients $(12,17)$. Notably, severe paraplegia was observed for the first time among the conditions of MBOAT7 gene defects, possibly resulting from truncal hypotonia and progressive spasticity and indicating the importance of early detection, timely treatment and regular follow-up observations to reduce the risk of such serious outcomes.

MBOAT7 is localized in the endoplasmic reticulum, mitochondria-associated membrane and lipid droplets, which play vital roles during the process of hepatic phospholipid remodeling and a non-canonical hepatic triglyceride synthesis pathway $(23,24)$. Increasing evidence indicates that the genetic variation of rs641738 in MBOAT7 increases the susceptibility risk to liver disease. However, none of our patients manifested relevant liver disease, likely because the patients are still very young.

Therefore, we suggest that a full neurological psychiatric assessment should be performed on patients with MBOAT7 gene defects, considering the variant in the presence of similar manifestations in children, particularly those from consanguineous families, so that it can help to benefit the early diagnosis and timely treatment for symptom alleviation and improvement of quality of life.

\section{CONCLUSION}

Our findings further confirm the association of the potential founder homozygous in-frame deletion (c. 758_778del; p. Glu253_Ala259del) in the MBOAT7 Gene and severe ID. The phenotypic characterization of ID in the two consanguineous Pakistani families expands the phenotypic spectrum of MBOAT7related ID. Therefore, we suggest targeted screening for the variant in relevant clinical circumstances.

\section{DATA AVAILABILITY STATEMENT}

The datasets generated for this study can be found in online repositories. The names of the repository/repositories and accession number(s) can be found at: https://www.ncbi.nlm.nih. gov/genbank/, NM_024298.5.

\section{ETHICS STATEMENT}

The studies involving human participants were reviewed and approved by Peking Union Medical College Institutional Review Board. Written informed consent to participate in this study was provided by the participants' legal guardian/next of kin. Written informed consent was obtained from the individual(s), and minor(s)' legal guardian/next of kin, for the publication of any potentially identifiable images or data included in this article.

\section{AUTHOR CONTRIBUTIONS}

LS and RW conducted Sanger sequencing, analysis of data, and manuscript writing. AK and RW clinically characterized patients, 
collected blood samples, and extracted DNA. HZ, SH, and $\mathrm{XH}$ assisted with the family analysis and PCR performance. XZ and RW designed the study and supervised the study progress. All authors read and approved the final manuscript.

\section{FUNDING}

National Key Research and Development Program of China (Grant numbers: 2016YFC0905100 and 2016YFC1000504), the

\section{REFERENCES}

1. Sharma N, Mishra R, Mishra D. The fifth edition of Diagnostic and Statistical Manual of mental disorders. (DSM-5): what is new for the pediatrician? Ind Pediatr. (2015) 52:141-3. doi: 10.1007/s13312-015-0589-y

2. Gustavson KH. Prevalence and aetiology of congenital birth defects, infant mortality and mental retardation in Lahore, Pakistan: a prospective cohort study. Acta Paediatr. (2005) 94:769-74. doi: 10.1111/j.1651-2227.2005.tb01981.x

3. Emanuel BS, Saitta SC. From microscopes to microarrays: dissecting recurrent chromosomal rearrangements. Nat Rev Genet. (2007) 8:86983. doi: $10.1038 / \mathrm{nrg} 2136$

4. Belkady B, Elkhattabi L, Elkarhat Z, Zarouf L, Razoki L, Aboulfaraj J, et al. Chromosomal abnormalities in patients with intellectual disability: a 21-year retrospective study. Hum Hered. (2018) 83:274-82. doi: 10.1159/000499710

5. Qiao Y, Mercier E, Dastan J, Hurlburt J, McGillivray B, Chudley AE, et al. Copy number variants. (CNVs) analysis in a deeply phenotyped cohort of individuals with intellectual disability. (ID). BMC Med Genet. (2014) 15:82. doi: 10.1186/1471-2350-15-82

6. Di Gregorio E, Riberi E, Belligni EF, Biamino E, Spielmann M, Ala U, et al. Copy number variants analysis in a cohort of isolated and syndromic developmental delay/intellectual disability reveals novel genomic disorders, position effects and candidate disease genes. Clin Genet. (2017) 92:41522. doi: $10.1111 /$ cge. 13009

7. Wieczorek D. Autosomal dominant intellectual disability. Med Genet. (2018) 30:318-22. doi: 10.1007/s11825-018-0206-2

8. Hamdan FF, Srour M, Capo-Chichi JM, Daoud H, Nassif C, Patry L, et al. De novo mutations in moderate or severe intellectual disability. PLoS Genet. (2014) 10:e1004772. doi: 10.1371/journal.pgen.1004772

9. Jamra R. Genetics of autosomal recessive intellectual disability. Med Genet. (2018) 30:323-7. doi: 10.1007/s11825-018-0209-z

10. Piton A, Redin C, Mandel JL. XLID-causing mutations and associated genes challenged in light of data from large-scale human exome sequencing. Am J Hum Genet. (2013) 93:368-83. doi: 10.1016/j.ajhg.2013.06.013

11. Najmabadi H, Hu H, Garshasbi M, Zemojtel T, Abedini SS, Chen W, et al. Deep sequencing reveals 50 novel genes for recessive cognitive disorders. Nature. (2011) 478:57-63. doi: 10.1038/nature10423

12. Hu H, Kahrizi K, Musante L, Fattahi Z, Herwig R, Hosseini M, et al. Genetics of intellectual disability in consanguineous families. Mol Psychiatr. (2019) 24:1027-39. doi: 10.1038/s41380-017-0012-2

13. Johansen A, Rosti RO, Musaev D, Sticca E, Harripaul R, Zaki M, et al. Mutations in MBOAT7, encoding lysophosphatidylinositol acyltransferase I, lead to intellectual disability accompanied by epilepsy and autistic features. Am J Hum Genet. (2016) 99:912-6. doi: 10.1016/j.ajhg.2016.07.019

14. Santos-Cortez RLP, Khan V, Khan FS, Mughal ZU, Chakchouk I, Lee K, et al. Novel candidate genes and variants underlying autosomal recessive neurodevelopmental disorders with intellectual disability. Hum Genet. (2018) 137:735-52. doi: 10.1007/s00439-018-1928-6
CAMS Innovation Fund for Medical Sciences (CIFMS) (Grant numbers: 2017-I2M-B\&amp;R-05 and 2016-I2M-1-002), and the National Natural Science Foundation of China (NSFC) (Grant numbers: 81230015 and 82001221 ).

\section{ACKNOWLEDGMENTS}

We are thankful for the members of the family for their participation and help in the study.

15. Khan S, Rawlins LE, Harlalka GV, Umair M, Ullah A, Shahzad S, et al. Homozygous variants in the HEXB and MBOAT7 genes underlie neurological diseases in consanguineous families. BMC Med Genet. (2019) 20:199. doi: 10.1186/s12881-019-0907-7

16. Yalnizoglu D, Ozgul RK, Oguz KK, Ozer B, Yucel-Yilmaz D, Gurbuz $\mathrm{B}$, et al. Expanding the phenotype of phospholipid remodelling disease due to MBOAT7 gene defect. J Inherit Metab Dis. (2019) 42:3818. doi: 10.1002/jimd.12016

17. Heidari E, Caddeo A, Zarabadi K, Masoudi M, Tavasoli AR, Romeo S, et al. Identification of novel loss of function variants in MBOAT7 resulting in intellectual disability. Genomics. (2020). doi: 10.1016/j.ygeno.2020. 07.008

18. Jacher JE, Roy N, Ghaziuddin M, Innis JW. Expanding the phenotypic spectrum of MBOAT7-related intellectual disability. Am J Med Genet B Neuropsychiatr Genet. (2019) 180:483-7. doi: 10.1002/ajmg.b.32749

19. Farnè M, Tedesco GM, Bedetti C, Mencarelli A, Rogaia D, Colavito D, et al. A patient with novel MBOAT7 variant: the cerebellar atrophy is progressive and displays a peculiar neurometabolic profile. Am J Med Genet A. (2020) 183:2377-83.doi: 10.1002/ajmg.a.61773

20. Li H, Handsaker B, Wysoker A, Fennell T, Ruan J, Homer N, et al. The sequence alignment/map format and SAMtools. Bioinformatics. (2009) 25:2078-9. doi: 10.1093/bioinformatics/btp352

21. Wang K, Li M, Hakonarson H. ANNOVAR: functional annotation of genetic variants from high-throughput sequencing data. Nucleic Acids Res. (2010) 38:e164. doi: 10.1093/nar/gkq603

22. Caddeo A, Jamialahmadi O, Solinas G, Pujia A, Mancina RM, Pingitore P, et al. MBOAT7 is anchored to endomembranes by six transmembrane domains. J Struct Biol. (2019) 206:349-60. doi: 10.1016/j.jsb.2019.04.006

23. Mancina RM, Dongiovanni P, Petta S, Pingitore P, Meroni M, Rametta $\mathrm{R}$, et al. The MBOAT7-TMC4 variant rs641738 increases risk of nonalcoholic fatty liver disease in individuals of european descent. Gastroenterology. (2020) 150:1219-30.e16. doi: 10.1053/j.gastro.2016. 01.032

24. Thangapandi VR, Knittelfelder O, Brosch M, Patsenker E, Vvedenskaya O, Buch S, et al. Loss of hepatic Mboat7 leads to liver fibrosis. Gut. (2020). doi: 10.1136/gutjnl-2020-320853

Conflict of Interest: The authors declare that the research was conducted in the absence of any commercial or financial relationships that could be construed as a potential conflict of interest.

Copyright (c) 2020 Sun, Khan, Zhang, Han, Habulieti, Wang and Zhang. This is an open-access article distributed under the terms of the Creative Commons Attribution License (CC BY). The use, distribution or reproduction in other forums is permitted, provided the original author(s) and the copyright owner(s) are credited and that the original publication in this journal is cited, in accordance with accepted academic practice. No use, distribution or reproduction is permitted which does not comply with these terms. 